\title{
Interpersonal interactions within couples: Convergences and divergences between self-description and partner's perception
}

\author{
Interações interpessoais em casais: \\ convergências e divergências entre \\ autodescrição e atribuição
}

\author{
Gleiber COUTO ${ }^{1,2}$ iD) 0000-0002-1139-811X \\ LUC VANDENBERGHE ${ }^{2}$ ID) 0000-0003-3252-3351 \\ Wanessa Marques TAVARES ${ }^{3}$ iD 0000-0002-9382-9576
}

\begin{abstract}
Conjugality refers to the shared experience between partners characterized by an enduring bond. It is related to a high degree of intimacy, affective involvement, and different interpersonal strategies, and it is seen by partners as their most significant relationship. Such intensity makes couple interaction different from any other type of relationship. The objective of this study was to verify how interpersonal attitude of the participants toward their spouses are associated with their partners and the independent interviewer's perception of their attitudes. The results showed that the participants had a perception of themselves that was, in general, congruent with their partners' and the interviewer's perception. However, the spouses agreed more about their relationship roles (dominant or submissive) and disagreed on the dedicated affection (friendly or hostile) between them. In contrast, the interviewer overestimated the subjects' attempts to control but confirmed the presence of statements of affection. The results obtained also provided a realistic portrait of marital interactions, increasing the application spectrum of the Checklist de Relações Interpessoais (Check list of Interpersonal Transactions).
\end{abstract}

Keywords: Interpersonal relations; Marriage; Psychological assessment; Test validity.

$\checkmark \nabla \nabla v$

1 Universidade Federal de Goiás, Instituto de Biotecnologia, Programa de Pós-Graduação em Gestão Organizacional. Av. Dr. Lamartine Pinto de Avelar, 1120, Setor Universitário, 75704-020, Catalão, GO, Brasil. Correspondência para/Correspondence to: G. COUTO. E-mail: <gleibercouto@yahoo.com.br>.

2 Pontifícia Universidade Católica de Goiás, Escola de Ciências Sociais e da Saúde, Curso de Psicologia, Programa de Pós-Graduação em Psicologia. Goiânia, GO, Brasil.

3 Prefeitura Municipal de Anhanguera, Secretaria de Ação Social, Centro de Referência de Assistência Social. Anhanguera, GO, Brasil. Support: Fundação de Apoio à Pesquisa do Estado de Goiás (no 006/2009, protocol 200910267000410).

Acknowledge: Fundação de Apoio à Pesquisa do Estado de Goiás.

$\boldsymbol{\nabla} \mathbf{\nabla} \boldsymbol{\nabla}$

Como citar este artigo/How to cite this article

Couto, G., Vandenberghe, L., \& Tavares, W. M. (2018). Interpersonal interactions within couples: Convergences and divergences between self-description and partner's perception. Estudos de Psicologia (Campinas), 35(3), 309-319. http://dx.doi.org/10.1590/1982-0 2752018000300009 


\section{Resumo}

A conjugalidade trata da vivência compartilhada entre os parceiros marcada pela continuidade do vínculo. Relaciona-se a um alto grau de intimidade, envolvimento afetivo e variabilidade de estratégias interpessoais, sendo idealizada como a relação mais significativa estabelecida pelos parceiros. Essa intensidade torna a interação de casal diferente de qualquer outra. Nosso objetivo foi verificar como posições interpessoais dos participantes com seus cônjuges se relacionam com posições atribuídas a eles pelos companheiros e entrevistadores independentes. Os resultados mostraram que os cônjuges têm uma percepção de si que corresponde, em geral, ao que o parceiro e o entrevistador têm a respeito deles, porém, cônjuges se entendem melhor sobre as direções do relacionamento (dominador ou submisso), enquanto discordam sobre o afeto dedicado (amigável ou hostil). Em contraste, o entrevistador superestima tentativas de controle enquanto confirma declarações de afeto. Também, providenciaram uma ilustração genuína das interações conjugais, ampliando a utilização do Checklist de Relações Interpessoais.

Palavras-chave: Relações interpessoais; Casamento; Avaliação psicológica; Validade do teste.

Conjugality refers to the coexistence between the partners within dyads, characterized by certain stability, enduring bond, high degree of intimacy, and affective involvement. Autonomous choice and the demand for exclusivity of romantic love relationships involve intimacy and expectations regarding complementarity and similarity between the members of the dyad (Montoya \& Horton, 2013).

Historically, the data in the literature have not demonstrated the same importance initially attributed to degree of complementarity in relationship dyads. In a review on couple complementarity and similarity, White and Hatcher (1984) found evidence suggesting that, on the one hand, similarities are more associated with attraction and satisfaction and marital success and are less associated with instability and divorce. On the other hand, in troubled relationships, complementarity appeared as a mechanism of stability and associated with spousal differences in level of general emotionalism. More recently, Cundiff, Smith, Butner, Critchfield, and NealeyMoore (2014) found that complementarity is present, but it varies according to the context; however, low anger and anxiety and greater relationship quality were associated with higher levels of affiliation and lower control.

Tensions are common in conjugal relationships due to the difficulty in meeting the high expectations of the partner, the high demand of high standards of oneself, and the demands resulting from the
Vandenberghe, 2009). In couple therapy, it has been observed the presence of a wide range of persistent interpersonal tactics that a partner uses in attempt to change the other or to solve problems arising from the interpersonal style of the partner. For example, hostile strategies such as questioning or refuting, invading the other's space, or blaming the partner, are present along with friendly strategies, such as resolving the conflict and waiting for the spouse to verbally open up. Similarly, submissive strategies, such as putting oneself in a vulnerable position or stepping back, are present along with dominant tactics, such as trying to persuade the other to accept one's ideas (saying one's truths) or putting oneself in a dominant position (Silva \& Vandenberghe, 2009).

This intensity and high variability in interpersonal strategies make couple interactions different from any other relationship. Partners hurt each other's feelings more and seem meaner or ruder to one another than to others. Lack of understanding and attempts to change the partner's behavior seem to be particularly common. On the other hand, the partners expose themselves more and are more open to the strategies of the other. Therefore, there is greater acceptance of behaviors and expressions of negative feelings than in other types of relationships (Silva \& Vandenberghe, 2009). Accordingly, Couto, Vandenberghe, and Tavares (2015) found that distrust, coldness, and hostility in a relationship were associated with higher number of complaints of mental suffering. Thus, intervention techniques based on emotional acceptance, 
tolerance building, and empathy have been extensively studied in the context of couple therapy (Briggs, Finley, \& Sprenkle, 2015). Some recent data have shown that the quality of communication between partners in a marital relationship can be pointed out as essential for relationship adjustment and satisfaction. Communication mediated the relationship between marital virtues, such as character strength, and relationship adjustment (Veldorale-Brogan, Bradford, \& Vail, 2010). Moreover, mutual communication style of couples appear to be positively associated with the general pattern of adjustment (Kazmi \& Pervez, 2013), which can be considered as a key factor in the positive development of romantic relationships (Määttä \& Uusiautti, 2013).

These findings support the importance of analyzing the interpersonal dynamics of couples. In the present study, it was assumed that in terms of relationship duration and intensity, certain patterns of interpersonal exchanges may characterize the interaction between couples. It was also assumed that these patterns of interaction incorporate the personal history of the spouses, their ideals, desires, and fantasies, as well as the family and cultural myths that each partner brings into the relationship. The focus was on the interactions, a "point" where the contributions and limitations of each partner meet and the interpersonal dynamics become visible.

Based on the aforementioned discussions regarding couple relationships, the objective of this study was to verify, in relationships considered satisfactory by the partners involved in it, how the participants' interpersonal behaviors towards their affective partners are associated with their respective partners' perceptions as well as the perceptions of third parties who analyzed their behaviors based on in-depth interview data on couple interactions. Therefore, convergence and divergence between their self-descriptions and perception of others (interacting partner and interviewer) will be presented. This study also examined the evidence of validity of the Checklist de Relações Interpessoais II (Check list of Interpersonal Transactions II), based on the evaluation of interpersonal interactions within couples.

\section{Method}

\section{Participants}

Thirty-two individuals not related to each other participated in this study, of which 16 were women aged between 18 and 51 years (Standard Deviation $[S D]=11$ ), living in the Southeastern region of Goiás. At the time of the study, 16 participants had domestic partnership, while the others were married. Their relationship duration ranged from 2 to 25 years (Media $[M]=9, S D=10$ ). The predominant socio-economic class was $B$, followed by class $C$. As for the participants' level of education, 11 people stated that they had a university degree, 16 had completed high school or were enrolled in higher education, while the others stated that they had incomplete secondary education.

\section{Instruments}

The "Checklist of Interpersonal TransactionsII" (CLOIT-II) is an inventory with 96 items designed to map the interpersonal behavior of target individuals. In the version for couples, participants completed a self-classification inventory checking the items that corresponded to their most frequent behaviors when interacting with their spouse. Similarly, the respective partners were asked to respond to the same items (interacting partner), evaluating the most frequent behaviors of his/her spouse during the interactions with him/her.

The items were divided into 16 two-dimensional segments organized in a quasi-circumplex internal structure and distributed around a circumference in an anticlockwise direction; they were named as follows: "Dominant" (A, $\alpha=0.72)$, "Competitive" (B, $\alpha=0.70)$, "Mistrusting" (C, $\alpha=0.74)$, "Cold" (D, $\alpha=0.67)$, "Hostile" ( $E, \alpha=0.62)$, "Detached" (F, $\alpha=0.71)$, "Inhibited" (G, $\alpha=0.72)$, "Unassured" $(H, \alpha=0.68)$, "Submissive" (I, $\alpha=0.70)$, "Deferent" $(J, \alpha=0.66)$, "Trusting" (K, $\alpha=0.64)$, "Warm" ( $L$, $\alpha=0.69)$, "Friendly" (M, $\alpha=0.69)$, "Sociable" ( $N$, $\alpha=0.68)$, "Exhibitionistic" (O, $\alpha=0.74)$, "Assured" (P, $\alpha=0.69$ ). The raw score ranged from zero to nine 
and was obtained by summing up the scores 1 or 2 , depending on the item checked by the participants. The 16 segments can be combined in "Quadrants": Hostile-Dominant (Qdt-HD, $\alpha=0.88$ ); HostileSubmissive (Qdt-HS, $\alpha=0.84$ ); Friendly-Submissive (Qdt-FS, $\alpha=0.84$ ); and Friendly-Dominant (Qdt-FD, $\alpha=0.83$ ) and Axes: Vertical Axis - Control (AXS-C, $\alpha=0.89$ ) and horizontal Axis - Affilia (AXS-A, $\alpha=0.87$ ) (Couto, Vandenberghe, Tavares, \& Silva, 2012).

Dyadic Adjustment Scale (DAS): a self-report inventory composed of 32 questions answered on a six or seven - point Likert scale. This instrument was designed to measure marital satisfaction according to the model of four interdependent dimensions developed by Spanier. This scale was adapted for the Brazilian population by Hernandez (2008), who reported adequacy of the internal structure and reliability indexes for its dimensions: consensus $(\alpha=0.86)$, cohesion ( $\alpha=0.76),(\alpha=0.62)$, satisfaction ( $\alpha=0.86)$, and total score ( $\alpha=0.93)$ (Hernandez, 2008).

"Abipeme Socio-economic Classification": a classification system developed by the Associação Brasileira dos Institutos de Mercado (Abipeme, Brazilian Association of Market Research Institutes), dividing the population into categories according to consumption patterns or consumption potentials. This classification includes five classes, A, B, C, D, and $E$, corresponding, respectively, to a determined score.

"In-depth Interview": a direct or personal loosely structured interview, in which a single respondent is evaluated by an interviewer to capture motivations, beliefs, attitudes, and perceptions of a given object. These interviews can be a good choice when research problems require a thorough understanding of complex behaviors.

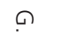

\section{Procedures}

The sample was selected from 169 couples who participated in a research on interpersonal marital relations approved by the Comitê de Ética em Pesquisa da Universidade Federal de Goiás (CEP-UFG), Protocol nº65/2010. The participants had already responded to the self-classification and interacting partner forms of the CLOIT-II and the DAS, and their socio-demographic data had already been collected. According to the objective proposed, 60 participants, randomly selected among those who showed good relationship adjustment/satisfaction (DAS>102), were invited to participate in an interview. A total of 32 participants accepted the invitation, and the interview was scheduled to be conducted on campus according to mutual availability. Participants were asked to answer the first or opening question, as follows: “... I would like to know a little more about your routine interactions with your partner, and also about how you behave, think, and feel in the relationship with your spouse". The interviews were divided and conducted by five interviewers independently. Each interview lasted between 50 minutes and 1 hour and 10 minutes. The researcher and the interviewers were blind to the results of the prior assessments in the first stage of the research.

\section{Data analysis}

At the end of the interview, each interviewer completed an evaluation protocol assigning scores to each subject's interaction patterns, according to the interpersonal circle proposed by Kiesler (1983). The results obtained by each subject were entered into a spreadsheet that contained the results of their self-descriptions and their partners' perceptions (CLOIT-II self-classification and interacting partner forms), as well as DAS, and socio-demographic data. The first step was to carry out the descriptive analyses (descriptive statistics) of the participants' results of the prior assessments. Subsequently, the participants' self-described interpersonal behaviors and their partners and interviewers' perceptions were compared. The paired sample $t$-test was used and the significance $(p)$, effect size (Glass's Delta), and Confidence Intervals $(95 \% \mathrm{Cl})$ of the differences between groups were calculated. Considering that interpersonal data were arranged in a quasi-circumplex structure, which is a nomological net with sinusoidal shape, each individual response could be reduced to its 
angular projection to describe an individual location within the circumference of the circle (Wright et al., 2012). Circular statistics and structural parameters were calculated: [ $\left(R^{2}\right)$ : Goodness of Fit; $(\delta)$ Angular Displacement; (e) Elevation, and (a) Amplitude]. At the end, the relationships between the interpersonal profile of the participants and their profile as perceived by their partner and the interviewer, respectively, were analyzed. The Pearson Correlation Coefficient $(r)$, the Coefficient of Determination $\left(R^{2}\right)$, and the Confidence Intervals (95\% Cl) between the scores of the self-classification and interacting partner forms and the scores assigned by the interviewer, respectively, were calculated. Correlations were calculated based on the raw correlations using the correction for attenuation formula $r_{12}^{*}=\frac{r_{12}}{\sqrt{r_{y y}}}$, where $r_{12}{ }^{*}$ is the corrected correlation, $r_{12}$ is the raw correlation between the two variables, and $r_{y y}$ is the reliability of the measure used to make the estimate. For the correction for attenuation, the alpha coefficients were estimated based on the matrix of tetrachoric correlations of each CLOIT-II scale using the data of the general sample, from which the participants of this research were selected.

\section{Results and Discussion}

The points of convergence and divergence were obtained by comparing the participants' description of their attitudes towards their affective partners (self-classification), their partners perception (interacting partner) of their attitudes toward them, and the interviewer's perception. The evaluation of the broader combinations of interpersonal interactions obtained from the scales used are shown in Table 1.

Table 1

Comparison of interpersonal attitudes between the groups evaluated

\begin{tabular}{|c|c|c|c|c|c|c|}
\hline Scales* & $\mathrm{M}$ & SD & $\mathrm{M}$ & SD & $p$ & Glass's $\Delta$ C195\%:(<;>) \\
\hline & \multicolumn{6}{|c|}{ Subject vs Partner } \\
\hline Axs_A & 16.18 & 10.06 & 13.25 & 13.75 & 0.28 & $0.29(-0.26 ; 0.84)$ \\
\hline Axs-C & -3.62 & 8.28 & 1.02 & 9.93 & 0.05 & $0.56(0.01 ; 1.11)$ \\
\hline Qdt-HD & 8.89 & 6.67 & 12.13 & 9.00 & 0.07 & $0.49(0.10 ; 1.04)$ \\
\hline Qdt-HS & 9.05 & 4.80 & 8.58 & 4.07 & 0.66 & $0.10(-0.45 ; 0.64)$ \\
\hline Qdt-FS & 21.36 & 7.94 & 18.95 & 8.00 & 0.25 & $0.30(-0.24 ; 0.85)$ \\
\hline \multirow[t]{2}{*}{ Qdt-FD } & 17.93 & 5.16 & 18.50 & 3.93 & 0.64 & $0.11(-0.43 ; 0.65)$ \\
\hline & \multicolumn{6}{|c|}{ Subject vs Interviewer } \\
\hline Axs_A & 16.18 & 10.06 & 16.32 & 12.70 & 0.94 & $0.01(-0.53 ; 0.56)$ \\
\hline Axs-C & -3.62 & 8.28 & 3.58 & 9.40 & 0.00 & $0.87(0.30 ; 1.44)$ \\
\hline Qdt-HS & 9.05 & 4.80 & 11.09 & 3.73 & 0.02 & $0.42(-0.12 ; 0.97)$ \\
\hline Qdt-FS & 21.36 & 7.94 & 21.08 & 6.77 & 0.85 & $0.04(-0.51 ; 0.58)$ \\
\hline \multirow[t]{2}{*}{ Qdt-FD } & 17.93 & 5.16 & 24.63 & 6.32 & 0.00 & $1.30(0.70 ; 1.90)$ \\
\hline & \multicolumn{6}{|c|}{ Partner vs Interviewer } \\
\hline Axs_A & 13.25 & 13.75 & 16.32 & 12.70 & 0.22 & $0.24(-0.30 ; 0.79)$ \\
\hline Axs-C & 1.02 & 9.93 & 3.58 & 9.40 & 0.26 & $0.27(-0.27 ; 0.82)$ \\
\hline Qdt-HD & 12.13 & 9.00 & 13.30 & 5.63 & 0.48 & $0.21(-0.34 ; 0.75)$ \\
\hline Qdt-HS & 8.58 & 4.07 & 11.09 & 3.73 & 0.00 & $0.67(0.11 ; 1.23)$ \\
\hline Qdt-FS & 18.95 & 8.00 & 21.08 & 6.77 & 0.14 & $0.31(-0.23 ; 0.86)$ \\
\hline Qdt-FD & 18.50 & 3.93 & 24.63 & 6.32 & 0.00 & $0.97(0.40 ; 1.54)$ \\
\hline
\end{tabular}

Note: *Axs_A: Affiliation Axis; Axs-C: Control Axis; Qdt-HD: Hostile-Dominant Quadrant; Qdt-HS: Hostile-Submissive Quadrant; Qdt-FS: Friendly-Submissive Quadrant; Qdt-AF: Friendly-Dominant Quadrant; FD: Standard Deviation; M: Media; 95\% Cl: 95\% Confidence Interval. 
First, the behaviors on the affiliation axis, which balances the characteristics of hostility vs. friendliness, and the control axis, which refers to dominance vs. submission behaviors were examined. The participants preferred friendliness behaviors to describe their interactions with their partners and both their partners and the interviewers agreed with these responses. However, they described themselves as more likely to have to submissive behaviors, while their partners considered them more dominant and the interviewers considered them as even more dominant. This suggests that the main differences found lie in the controlling behaviors, which are estimated less intense by the subjects themselves than by their partners, and perhaps overestimated by the interviewers.

On the other hand, the participants' tendency to emphasize qualities related to friendliness when describing their interactions with their partners was confirmed by the descriptions made by their partners and the interviewers. Thus, with regard to the friendly pole of the affiliation axis, as stated by Kazmi and Pervez (2013) and Määttä and Uusiautti (2013), it is plausible that individuals in a stable and satisfactory affective relationship tend to have a level of communication with the partner that reflects in the couple's similar perception of affective quality of the interpersonal exchanges between them.

As for the power struggle in the relationship, significant differences showed that the interviewers tended to perceive more behaviors of dominance and hostility (both passive and active) in the participants than those perceived by the participants themselves. The effect size, i.e., the size of the difference between the subjects and their partners in the hostility-dominance quadrant suggests the possibility that active hostile behaviors are also more likely to be pointed out by the partners than by the subjects themselves.

Due to these discrepancies between the interpersonal behaviors perceived by the subjects themselves and those perceived by the partners and interviewers, it was assumed that there was a behavior in the interpersonal circle that is typical

314 for each source of information. Therefore, the structural parameters and circular statistics were calculated. The low $R^{2}$ values $(0.40,0.25,0.30)$ and amplitude values $(0.15,0.10,0.35)$ found indicated, for the three different sources of information, that there was no "interpersonal prototypicality", which is expected in randomly formed groups. Therefore, the participants' behaviors cannot be summarized based on a specific interpersonal theme. According to this observation, it is speculated that the conjugal adjustment is not associated with the presence of a typical interpersonal theme but rather with the specific characteristics of the couple's interaction. Moreover, the elevation values $(-0.07,0.01$; 0.30 ) did not show interpersonal stress for any of the descriptions, which is in agreement with the results found by Couto et al. (2015). Since a typical behavior was not identified, the distribution of the descriptions of the groups over the circle was considered based on the circular statistics. The Confidence Intervals (95\% Cl) showed that the subjects described themselves with behaviors located in the region of the circle from confidence $\left(K, 323.09^{\circ}\right)$ to affective warmth $\left(L, 341.92^{\circ}\right)$. Their partners' perceptions show interpersonal behaviors from sociability $\left(\mathrm{N}, 12.97^{\circ}\right)$ to exhibitionistic $(\mathrm{O}$, $\left.46.54^{\circ}\right)$. On the other hand, the interviewers described the subjects with behaviors in the region from exposure $\left(0,43.31^{\circ}\right)$ to dominant $\left(A, 95.22^{\circ}\right)$, showing some overlap with the description of the partners. This result corroborates the hypothesis about the underestimation of behaviors more related to dominance in the self-descriptions. It was also found that the interviewers' perceptions were the most similar $\left(\sigma^{2}=67.51^{\circ}\right)$, while the highest interpersonal diversity was found in the subjects' self-descriptions $\left(\sigma^{2}=88.33^{\circ}\right)$, corroborating the findings of Silva and Vandenberghe (2009) and Couto et al. (2015).

Due to the heterogeneity of the interpersonal behaviors mentioned by the different information sources, the discrepancies were closely examined aiming to determine how they could be understood based on more specific patterns of interactions. Thus, the scores in the 16 segments of the interpersonal circle were used to draw a map of the interpersonal behaviors of the participants. Figure 1 shows this map highlighting the points of convergence and 


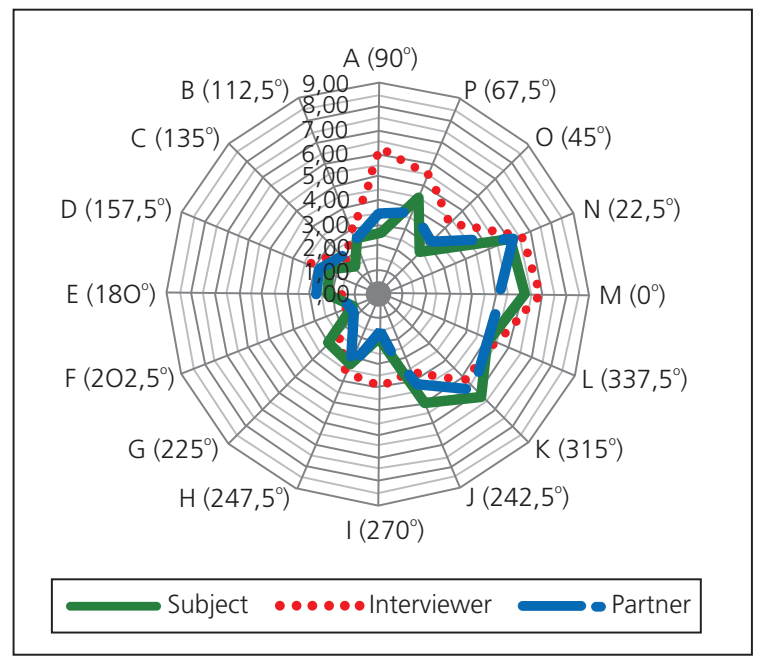

Figure 1. Comparison between interpersonal attitudes admitted by subjects and perceived by their partners in affective relationships.

Note: "Dominant" (A), "Competitive" (B), "Mistrusting" (C), "Cold" (D), "Hostile" (E), "Detached" (F), "Inhibited" (G), "Unassured" (H), "Submissive" (I), "Deferent" (J), "Trusting" (K), "Warm" (L), "Friendly" (M), "Sociable" (N), "Exhibitionistic" (O), "Assured" (P).

divergence between the measures obtained from the three sources of information.

Firstly, it was observed that the discrepancies between the participants and their partners in the interpersonal behaviors on the control axis were better explained by the significant differences in the following segments: Mistrusting $[T(2,62)=$ -2.92; $p=0.007]$, with Glass's $\Delta=0.66$ [95\% Cl: $(0.10 ; 1.21)]$; Inhibited $[\mathrm{T}(2.62)=3.41 ; p<0.002]$ with Glass's $\Delta=0.66$ [95\% Cl: $(0.11 ; 1.21)]$; and Exhibitionistic $[F(2.62)=-2.13 ; p<0.04)$, with Glass's $\Delta=0.66(95 \% \mathrm{Cl}: 0.10,1.22)$. These results suggest that the partners perceive the subjects as more fearful, more spontaneously expressive, and less reserved than they feel. Whereas, as for the interviewers' perceptions, the discrepancies were better explained by the significant differences in the following segments: Exhibitionistic $[T(2,62)=-3.99$; $p<0.001$ ], with Glass's $\Delta=1.39$ (95\% Cl: 0.79, 2.00); Assured [T (2.62) $=-2.09 ; p<0.05]$, with Glass's $\Delta=$ 0.59 (95\% Cl: 0.03; 1.14); and Dominant [T (2.62) $=-7.28 ; p<0.000]$, with Glass's $\Delta=1.84(95 \%$ $\mathrm{Cl}: 1.19 ; 2.29)$, suggesting that the interviewers perceive the subjects as having a certain tendency to show exaggerated expression of emotions in their interactions with their partners and that they are more persuasive and secure than they admit, at least during the interview. The discrepancies in mistrusting $[T(2,62)=2.43 ; p<0.02)$, with Glass's $\Delta=0.46$ (95\% Cl: $0.09,1.01)$ and Deferent [T $(2.62)=$ 2.14; $p<0.04)$, with Glass's $\Delta=0.57[95 \% \mathrm{Cl}$ : $0.02 ; 1.13)$ ] showed that the interviewers perceive the subjects as more suspicious and less attentive to their partners than they admit.

Secondly, it was observed that the partners and interviewers had different perceptions of some of the subject's behaviors. On the one hand, the interviewers perceived more exaggerated emotional expressions \{exhibitionistic $[\mathrm{T}(2,62)=-1.95 ; p=$ 0.062 ], with Glass's $\Delta=0.53$ [95\% Cl: $(0.03 ; 1.08)$ ]; confidence assured $[\mathrm{T}(2.62)=-3.48 ; p=0.002]$, with Glass's $\Delta=0.75$ [95\% Cl: $0.19 ; 1.31)]\} ;$ and control \{Dominant [T $(2.62)=4.43 ; p=0.000]$, with Glass's $\Delta=1.10[95 \% \mathrm{Cl}: 0.51 ; 1.68)]\}$ in the subjects than their partners. The partners agreed more with the subjects' own perception of these characteristics. On the other hand, the partners perceived higher levels of hostility [ $\mathrm{T}(2$, $62)=2.34 ; p=0.027$ ], with Glass's $\Delta=0.54$ [95\% $\mathrm{Cl}:(0.01 ; 1.10)]$ and lower levels of inhibition $[\mathrm{t}$ $(2.62)=-3.80 ; p=0.001]$, with Glass's $\Delta=0.60$ [95\% Cl: $(0.04 ; 1.15)]$ and friendliness $[\mathrm{T}(2.62)=-3.26$; $p=0.003$ ], with Glass's $\Delta=0.84$ [95\% Cl: 0.28 ; 1.41)] in the subjects than the interviewers, who, in this case, tended to agree more with the subjects' perceptions of themselves. It seems that the partners' perceptions tend to be more similar on the control axis than that of an external observer, who tend to overestimate these characteristics. However, the partners disagreed over emotional quality, and the observer tended to agree more with the subjects on this characteristic. In other words, it can be said that, while the partners focus more on affection, the interviewers were more focused on issues such as "who is in charge in the relationship".

Based on these findings about interpersonal behaviors in affective relationships, the associations between the subjects' self-descriptions and their partners' perceptions were determined. The results of significant correlations and effect size, obtained 
by the coefficient of determination $\left(R^{2}\right)$ and confidence intervals $(95 \% \mathrm{CI})$, are shown in Table 2 .

Considering the coincidences between the self-descriptions and the partners' perceptions of the same characteristic, the results (highlighted) showed substantial, significant positive correlations among the segments: Mistrusting (C), Inhibited (G), Submissive, (I) and Warm (L). This result confirms the hypothesis about the role of communication in a relationship (Veldorale-Brogan et al., 2010), allowing the assumption that that people in relationships that they consider as satisfactory tend to perceive and strongly agree with the attitudes of their partners, when theses attitiudes represent a certain of fear of misinterpretation, distrust, shyness, tendency to take advice, sweetness, tolerance, and affection.

Another issue investigated was how certain partners' perceptions are associated with the behaviors perceived by the subjects themselves. Therefore, the correlations between each description made by the subjects and those made by their partners were analyzed. For example, considering the attitudes in the hostile-dominant quadrant, although they were not very frequent in the behavioral repertoire of these individuals, their self-description about dominance $(A)$ showed a substantial, negative significant correlation with confidence $(\mathrm{K})$. It is worth mentioning that since they refer to the correlation coefficients, the interpretations in this section do not have a causal explanatory character, and they can also be seen a two-way street. Thus, more attempts to take control and demonstrate their qualities in the interactions were associated with less perceptions of dedication and trust in the relationship, or vice versa. Similarly, the more the expressions of distrust $(C)$, the more the perceptions of dominance (A), competition (B), coldness (D), and hostility (E) attributions. These

Table 2

Correlations between self-description and partner's perception

\begin{tabular}{|c|c|c|}
\hline \multicolumn{3}{|c|}{ Scale $\left[r\left(R^{2}\right) ; C 195 \%:(<;>)\right]$} \\
\hline A & - & $K\left[-0.55^{\mathbf{b}}(0.30) ; \mathrm{C} 195 \%:(-0.60 ;-0.13)\right]$ \\
\hline \multirow{5}{*}{ C } & $\mathrm{A}\left[0.63^{\mathrm{a}}(0.40) ; \mathrm{C} 195 \%:(0.30 ; 0.87)\right]$ & \\
\hline & $\mathrm{B}\left[0.63^{\mathrm{a}}(0.40) ; \mathrm{C} 195 \%:(0.36 ; 0.83)\right]$ & \\
\hline & $\mathrm{C}\left[0.71^{\mathrm{a}}(0.50) ; \mathrm{Cl} 95 \%:(0.41 ; 0.94)\right]$ & $\mathrm{K}\left[-0.48^{\mathbf{b}}(0.23) ; \mathrm{C} 195 \%:(-0.65 ;-0.11)\right]$ \\
\hline & $\mathrm{D}\left[0.54^{\mathbf{b}}(0.29) ; \mathrm{Cl} 95 \%:(0.18 ; 0.54)\right]$ & \\
\hline & $\mathrm{E}\left[0.69^{\mathbf{b}}(0.48) ; \mathrm{Cl95 \%}:(0.35 ; 0.91)\right]$ & \\
\hline \multirow{2}{*}{ D } & \multirow{2}{*}{$\mathrm{F}\left[0.57^{\mathbf{b}}(0.32) ; \mathrm{Cl} 95 \%:(0.20 ; 0.75)\right]$} & J [-0.69a $(0.48) ; C 195 \%:(-0.90 ;-0.27)]$ \\
\hline & & $K\left[-0.69^{a}(0.48) ; C 195 \%:(-0.88 ;-0.38)\right]$ \\
\hline \multirow{3}{*}{ G } & B $\left[0.63^{\mathbf{b}}(0.40) ; \mathrm{C} 195 \%:(-0.32 ; 0.81)\right]$ & \multirow{3}{*}{-} \\
\hline & $\mathrm{E}\left[0.45^{\mathrm{c}}(0.20) ; \mathrm{Cl} 95 \%:(0.12 ; 0.71)\right]$ & \\
\hline & $\mathrm{G}\left[0.53^{\mathrm{b}}(0.28) ; \mathrm{Cl} 95 \%:(0.20 ; 0.81)\right]$ & \\
\hline \multirow{2}{*}{ I } & \multirow{2}{*}{ B $\left[0.42^{\mathrm{C}}(0.18) ; \mathrm{Cl} 95 \%:(-0.17 ; 0.76)\right]$} & I [0.62 $\left.{ }^{\mathrm{b}}(0.38) ; \mathrm{Cl} 95 \%:(0.17 ; 0.73)\right]$ \\
\hline & & $\mathrm{O}\left[0.42^{\mathrm{C}}(0.18) ; \mathrm{Cl} 95 \%:(0.05 ; 0.70)\right]$ \\
\hline J & B $\left[-0.45^{\mathrm{c}}(0.20) ; \mathrm{C} 195 \%:(0.11 ; 0.71)\right]$ & $\mathrm{P}\left[0.70^{\mathrm{a}}(0.49) ; \mathrm{Cl} 95 \%:(-0.39 ; 0.91)\right]$ \\
\hline \multirow{2}{*}{ L } & \multirow{2}{*}{$D\left[-0.55^{\mathbf{b}}(0.30) ; C 195 \%:(-0.80 ;-0.22)\right]$} & L [0.60 (0.36); Cl95\%: $(0.30 ; 0.84)]$ \\
\hline & & $\mathrm{P}\left[0.54^{\mathbf{b}}(0.29) ; \mathrm{Cl} 95 \%:(0.14 ; 0.82)\right]$ \\
\hline M & - & $P\left[0.39^{c}(0.15) ; C 195 \%:(0.17 ; 0.71)\right]$ \\
\hline N & & $P\left[0.62^{\mathrm{a}}(0.38) ; \mathrm{C} 195 \%:(0.32 ; 0.81)\right]$ \\
\hline O & $\mathrm{A}\left[0.58^{\mathbf{b}}(0.34) ; \mathrm{C} 195 \%:(0.23 ; 0.83)\right]$ & $J\left[-0.41^{c}(0.17) ; C 195 \%:(-0.70 ; 0.10)\right]$ \\
\hline$P$ & - & $\mathrm{J}\left[-0.65^{\mathbf{b}}(0.42) ; \mathrm{Cl} 195 \%:(-0.88 ; 0.00)\right]$ \\
\hline
\end{tabular}

Note: ${ }^{a} p<0.01 ;{ }^{b} p<0.05 ;{ }^{c} p>0.05$ and $<0.10$.

$A=0.76 ; B=0.71 ; C=0.77 ; D=0.65 ; E=0.74 ; F=0.71 ; G=0.55 ; \quad H=0.44 ; I=0.64 ; J=0.55 ; K=0.70 ; L=0.66 ; M=0.75 ; N=0.71 ; O=0.67 ; P=0.51$. The items in bold show the correlations between self-description and partiner's perception on the same scale. 
positive associations are expected because they are behaviors in the same quadrant of the circle. Furthermore, expressions of coldness (D) were associated with isolation (F) and lower sense of deference $(J)$ and confidence (K). Similarly, negative associations between the last two behaviors ( $\mathrm{J}$ and K) and D were expected because they are located in opposite quadrants. These correlations are in agreement with the theoretical conceptions of the interpersonal circle proposed by Kiesler (1983).

With regard to the Hostile-Submissive quadrant (HS), it can be observed that a certain degree of prolixity and frequent attempts to explain themselves $(G)$ are associated with perceptions of attempts to stand out or to be right about the partner (B), as well as with a certain discomfort or annoyance due to the partner's presence $(E)$. In the friendly-submissive quadrant, it was observed that dedication and expressions of satisfaction (M) are perceived as feelings of a secure relationship.
Similarly, the more the subjects perceive themselves as warm (L), the less cold (D) and more secure (P) they are perceived by their partners, or vice versa. However, social behaviors ( $N$ ) were associated with expressions of security $(\mathrm{P})$. The more spontaneous and impulsive $(O)$, the greater the perception of control (A); while impulsivity (O) and security expressions $(P)$ were associated with less perceptions of deference (J) by the partners. The associations found are consistent with data reported on the literature on the effects of communication on couple relationships (Kazmi \& Pervez, 2013; Määttä \& Uusiautti, 2013; Veldorale-Brogan et al., 2010).

The last issue examined was related with how the subject's self-descriptions were associated with the interviewers' perceptions. This analysis was based on the overall perceptions in situations where both partners talk about their relationships. The results presented in Table 3 show the correlations, determination coefficients $\left(R^{2}\right)$, and confidence

Table 3

Correlations between self-description and interviewer's perception

\begin{tabular}{|c|c|c|}
\hline \multicolumn{3}{|c|}{ Scale $\left[r\left(R^{2}\right) ;\right.$ C195\%: $\left.(<;>)\right]$} \\
\hline C & $\begin{array}{l}C\left[0.65^{\mathrm{a}}(\mathbf{0 . 4 2 )}) \text { C195\%: }(0.24 ; 0.84)\right] \\
E\left[0.76^{\mathrm{a}}(0.58) ; C 195 \%:(0.26 ; 0.90)\right]\end{array}$ & $\begin{array}{l}\text { I }\left[-0.43^{\mathrm{C}}(0.18) ; \mathrm{CI} 95 \%:(-0.80 ;-0.13)\right] \\
\text { K }\left[-0.68^{\mathrm{c}}(0.46) ; \mathrm{CI} 95 \%:(-0.80 ;-0.44)\right] \\
\text { P }\left[-0.41^{\mathrm{C}}(0.17) ; \mathrm{CI} 95 \%:(-0.75 ;-0.10)\right]\end{array}$ \\
\hline $\mathrm{F}$ & $\mathrm{D}\left[0.68^{\mathrm{a}}(0.46) ; \mathrm{C} 195 \%:(0.37 ; 0.86)\right]$ & - \\
\hline G & 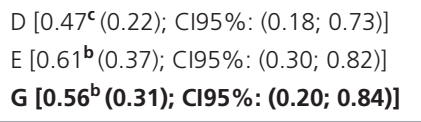 & - \\
\hline I & $\mathrm{B}\left[-0.63^{\mathbf{b}}(0.40) ; \mathrm{C} 195 \%:(-0.82 ;-0.42)\right]$ & I $\left[0.61^{\mathrm{b}}(0.37) ; \mathrm{Cl} 95 \%:(0.16 ; 0.87)\right]$ \\
\hline K & - & $\begin{array}{l}\text { L }\left[0.51^{\mathbf{b}}(0.26) ; C 195 \%:(0.13 ; 0.70)\right] \\
\text { M }\left[0.55^{\mathbf{b}}(0.30) ; C 195 \%:(0.12 ; 0.78)\right] \\
\text { N }\left[0.65^{\mathbf{b}}(0.42) ; C 195 \%:(0.20 ; 0.86)\right] \\
\text { P }\left[0.43^{\mathbf{c}}(0.18) ; C 195 \%:(0.11 ; 0.67)\right]\end{array}$ \\
\hline $\mathrm{L}$ & $\begin{array}{l}C\left[-0.53^{\mathrm{c}}(0.28) ; C 195 \%:(-0.83 ;-0.13)\right] \\
E\left[-0.61^{\mathrm{a}}(0.37) ; \mathrm{CI} 95 \%:(-0.86 ;-0.16)\right]\end{array}$ & 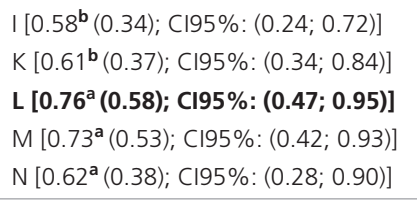 \\
\hline M & - & $\begin{array}{l}\text { M [0.50b (0.25); CI95\%: }(0.20 ; 0.76)] \\
\text { N [0.44b }(0.19) ; C 195 \%:(0.10 ; 0.79)] \\
\text { P [0.45c }(0.20) ; C 195 \%:(0.13 ; 0.69)]\end{array}$ \\
\hline $\mathrm{N}$ & - & L $\left[0.49^{\mathbf{b}}(0.24) ; C 195 \%:(0.10 ; 0.78)\right]$ \\
\hline
\end{tabular}

Note: ${ }^{a} p<0.01 ;{ }^{b} p<0.05 ;{ }^{c} p>0.05$ and $<0.10$.

$A=0.76 ; B=0.71 ; C=0.77 ; D=0.65 ; E=0.74 ; F=0.71 ; G=0.55 ; H=0.44 ; I=0.64 ; J=0.55 ; K=0.70 ; L=0.66 ; M=0.75 ; N=0.71 ; O=0.67 ; P=0.51$. The items in bold show the correlations between self-description and partiner's perception on the same scale. 
intervals (95\% Cl) between the subjects' self-descriptions and the interviewers' perceptions.

Considering the coincidences between the self-description and the interviewers' perceptions of the same characteristic, the results (highlighted) showed substantial, significant positive correlations among mistrusting (C), inhibited (G), submissive (I) and affective warmth (L). This suggests that the interviewers and subjects had similar perceptions in terms of the subjects' fear of being misinterpreted or deceived (C), difficulties in expressing themselves $(\mathrm{G})$, and passivity (I), as well as when they describe themselves as warm and loving $(\mathrm{L})$.

Accordingly, with regard to the correlations between each subjects'-self description and the behaviors perceived by the interviewers, it was observed that behaviors of distrust (C) perceived by the subjects were associated with the interviewers' perceptions of insensitivity or interpersonal hostility (E). Moreover, negative correlations suggest perceptions of lack of willingness to accept advices and suggestions (I), confidence (K), and security in interactions $(P)$. These results suggest that, in this case, the descriptions of interactions marked by more active behaviors, especially those related to ambition and distrust, are strongly associated with the interviewers' perceptions of absence of positive affect and confidence. On the other hand, selfdescriptions of Submission (I) were less associated with perceptions of competition (B). The more the expressions of trust $(K)$ in people, the more the perceptions of affective warmth $(\mathrm{L})$, friendliness $(\mathrm{M})$, sociability (N), and security (P). Furthermore, the higher the level of affective warmth $(\mathrm{L})$, the greater the association with perceptions of submission $(I)$, confidence $(K)$, friendliness $(M)$, sociability $(N)$, and absence of distrust and hostility. These results suggest that passive behaviors with positive affect lead to the perception of kindness.

\section{Final Considerations}

The results of this study showed that the spouses' perception of their own behavior tend to be similar to that of their partner and fact that they believe that they exhibit a friendly behavior, which is congruent with their partner and observer's perceptions. Other authors (Couto et al., 2015) have shown that the clear prevalence of friendly interpersonal behaviors and low level of hostility distinguish couples who have a healthy relationship from those who have complaints of mental suffering. Dysfunctional relationships have a greater variety and less congruence of intense interpersonal attitudes, showing both hostile and friendly interactions.

On the other hand, the subjects in the present study tended to perceive themselves as more submissive than how partner and the external observer perceive them. Attitudes of distrust and impulsiveness, which are negative characteristics of couple interaction, are less present in the selfdescriptions of the spouse. Moreover, there were strong associations between more active patterns of interaction and negative affect and between passive patterns of interaction and positive affect. This study also examined the evidence of validity of the Checklist de Relações Interpessoais - II, aiming at expanding the interpretations of this instrument for use in the Brazilian population, providing psychometric data that increases its application spectrum in studies on interpersonal interactions within couples.

The small number of participants and the fact that they were selected using convenience sampling limit generalization of the data obtained and have a direct impact on the stability of the correlation coefficients determined. In particular, they affect the probability of correctly rejecting the null hypothesis and, consequently, they influence the effect of the results for the population in general.

Based on the aforementioned discussions, it can be said that the data obtained corroborate those reported in the literature on interactions between spouses and their communication, health, and satisfaction. The results obtained also provided a realistic portrait of marital interactions, and they can be used to support congruent interpretations in conjugal therapy. Further studies are needed to replicate and extend these findings. 


\section{Contributors}

G. COUTO contributed to the conception and design of this study, to data analysis and interpretation, and to the revision and approval of the final version. L. VANDENBERGHE contributed to data analysis and interpretation, and to the revision and approval of the final version. W.M. TAVARES contributed to the revision and approval of the final version.

\section{References}

Briggs, J. B., Finley, M. A., \& Sprenkle, D. H. (2015). A Substantive and methodological review of the integrative behavioral couple therapy research program: Clinical implications for a research informed practice. Journal of Couple and Relationship Therapy, 14(3), 219-253. http://dx.doi.org/10.1080/1533269 1.2014 .959229

Couto, G., Vandenberghe, L. M. A., Tavares, W. M., \& Silva, R. L. F. C. (2012). Interações e habilidades sociais entre universitários: um estudo correlacional. Estudos de Psicologia (Campinas), 29(Supl), 667S-6775. http:// dx.doi.org/10.1590/S0103-166X2012000500003

Couto, G., Vandenberghe, L., \& Tavares, W. M. (2015). Interpersonal interactions in the marital pair and mental health: A comparative and correlational study. Paidéia, 25(62), 373-382. http://dx.doi.org/10. 1590/1982-43272562201511

Cundiff, J. M., Smith, T. W., Butner, J., Critchfield, K. L., \& Nealey-Moore, J. (2014). Affiliation and control in marital interaction interpersonal complementarity is present but is not associated with affect or relationship quality. Personality and Social Psychology Bulletin, 41(1) 35-51. http://dx.doi.org/10.1177/0146167214557002

Hernandez, J. A. E. (2008). Avaliação estrutural da escala de ajustamento diádico. Psicologia em Estudo, 13(3), 593-601. http://dx.doi.org/10.1590/\$1413-737 22008000300021
Kazmi, S. F., \& Pervez, T. (2013). Marital adjustment of educated working and educated non working women as a factor of communication style with their spouses. International Journal of Physical and Social Sciences, 3(1), 1-16.

Kiesler, D. J. (1983). The 1982 Interpersonal Circle: A taxonomy for complementarity in human transactions. Psychological Review, 90(3), 185-214. http://dx.doi. org/10.1037/0033-295X.90.3.185

Määttä, K., \& Uusiautti, S. (2013). Silence is not golden: Review of studies of couple interaction. Communication Studies, 64(1), 33-48. http://dx.doi.org/10.10 80/10 510974.2012.731467

Montoya, R. M., \& Horton, R. S. (2013). A metaanalytic investigation of the processes underlying the similarity-attraction effect. Journal of Social and Personal Relationships, 30(1), 64-94. http://dx.doi. org/10.1177/0265407512452989

Silva, L. P., \& Vandenberghe, L. (2009). Comunicação versus resolução de problemas numa sessão única de terapia comportamental de casal. Revista Brasileira de Terapia Comportamental e Cognitiva, 11(1), 43-60.

Veldorale-Brogan, A., Bradford, K., \& Vail, A. (2010). Marital virtues and their relationship to individual functioning, communication, and relationship adjustment. The Journal of Positive Psychology, 5(4), 281-293. http://dx.doi.org/10.1080/17439760.201 0.498617

White, S. G., \& Hatcher, C. (1984). Couple complementarity and similarity: A review of the literature. American Journal of Family Therapy, 12(1), 15-25. http://dx.doi. org/10.1080/01926188408250155

Wright, A. G., Pincus, A. L., Hopwood, C. J., Thomas, K. M., Markon, K. E., \& Krueger, R. F. (2012). An interpersonal analysis of pathological personality traits in DSM-5. Assessment, 19(3), 263-275. http://dx.doi. org/ 10.1177/1073191112446657

Received: August 29, 2016

Final version: February 24, 2017

Approved: April 6, 2017 